\title{
Toll-Like Receptor-7 Signaling Promotes Nonalcoholic Steatohepatitis by Inhibiting Regulatory T Cells in Mice
}

Yoon Seok Roh, ${ }^{*}$ Jong Won Kim, ${ }^{\dagger}$ Surim Park, ${ }^{\dagger}$ Changho Shon, ${ }^{*}$ Sokho Kim, ${ }^{\dagger}$ Seong Kug Eo, ${ }^{\dagger}$ Jung Kee Kwon, ${ }^{\dagger}$ Chae Woong Lim, and Bumseok Kim

From the Department of Pharmacy, * College of Pharmacy and Medical Research Center, Chungbuk National University, Cheongju, Chungbuk; and the Biosafety Research Institute and College of Veterinary Medicine (BK21 Plus Program), ${ }^{\dagger}$ Chonbuk National University, Iksan, Jeonbuk, Republic of Korea

Accepted for publication

July 10, 2018.

Address correspondence to Bumseok Kim, D.V.M., Ph.D., Laboratory of Pathology, College of Veterinary Medicine, Chonbuk National University, Iksan, Jeonbuk 54596, South Korea. E-mail: bskims@jbnu.ac.kr.

\begin{abstract}
Toll-like receptor 7 (TLR7) signaling regulates the production of type 1 interferons (IFNs) and proinflammatory cytokines, such as tumor necrosis factor (TNF)- $\alpha$, implicated in the control of regulatory $T$ (Treg) cell activity. However, the mechanistic interplay between TLR7 signaling and Treg cells in nonalcoholic steatohepatitis (NASH) has not been elucidated. Our aim was to clarify the role of TLR7 signaling in the pathogenesis of NASH. Steatohepatitis was induced in wild-type (WT), TLR7-deficient, IFN- $\alpha / \beta$ receptor 1 -deficient, and Treg cell-depleted mice. TLR7-deficient and IFN- $\alpha / \beta$ receptor 1 -deficient mice were more protective to steatohepatitis than WT mice. Of interest, both TNF- $\alpha$ and type 1 IFN promoted apoptosis of Treg cells involved in the prevention of NASH. Indeed, Treg cell-depleted mice had aggravated steatohepatitis compared with WT mice. Finally, treatment with immunoregulatory sequence 661 , an antagonist of TLR7, efficiently ameliorated NASH in vivo. These results demonstrate that TLR7 signaling can induce TNF- $\alpha$ production in Kupffer cells and type I IFN production in dendritic cells. These cytokines subsequently induce hepatocyte death and inhibit Treg cells activities, leading to the progression of NASH. Thus, manipulating the TLR7-Treg cell axis might be used as a novel therapeutic strategy to treat NASH. (Am J Pathol 2018, 188: 2574-2588; https://doi.org/10.1016/j.ajpath.2018.07.011)
\end{abstract}

Nonalcoholic fatty liver disease (NAFLD) is a major form of chronic liver diseases in adults and children. ${ }^{1}$ Nonalcoholic steatohepatitis (NASH) is characterized by simple steatosis, hepatitis, and progressive fibrosis. It can ultimately lead to end-stage liver disease. ${ }^{2} \mathrm{NASH}$ has been observed in a subset of patients with NAFLD. However, the exact mechanisms by which a simple steatosis leads to NASH remain poorly understood.

Recent studies have suggested that overgrowth of intestinal bacteria and increased intestinal permeability might play roles in the development of NASH. ${ }^{3-5}$ In chronic liver diseases, including NASH, intestinal permeability is increased because of bacterial overgrowth or altered compositions of bacterial microflora. ${ }^{6}$ Systemic inflammation related to NASH also injures epithelial tight junctions, ${ }^{3}$ resulting in deregulation of intestinal barrier functions. Indeed, plasma levels of lipopolysaccharides (LPSs) are elevated in patients with chronic liver diseases, including NASH. ${ }^{7}$ These findings suggest that hepatic immune cells might be exposed to high levels of Toll-like receptor (TLR) ligands derived from gut bacterial products, which might trigger liver injury and progress to NASH. Several reports have detailed the importance of TLR4 and intestine-derived LPS in animal models of NASH. ${ }^{8,9}$ Recently, it has been revealed that TLR7, initially considered a receptor of single-stranded RNA virus, can also recognize RNA from

Supported by Basic Science Research Program grant NRF2017R1D1A3B03030521 (B.K.) through the National Research Foundation funded by the Ministry of Education, Republic of Korea; Ministry of Science and Information and Communications Technology grant MRC 2017R1A5A2015541 (Y.S.R.); and Ministry of Health and Welfare, Republic of Korea grant HI17C2262 (Y.S.R.).

Y.S.R., J.W.K., and S.P. contributed equally to this work.

Disclosures: None declared. 
bacteria. ${ }^{10,11}$ Furthermore, host-derived denatured RNA from apoptotic cells can also be recognized by TLR7 as an endogenous ligand. ${ }^{12,13}$ As a consequence, hepatic immune cells might be exposed to effective levels of TLR7 ligands after liver injury, thus playing a role in the pathogenesis of NASH. Indeed, TLR4- or TLR9-deficient mice have exhibited reduced liver injury and NASH induced by a methionine-choline-deficient (MCD) or choline-deficient amino acid-defined diet, ${ }^{9,14}$ indicating that TLR ligands originated from bacteria (bacterial LPS or DNA) or host (host DNA) might play a crucial role in NASH pathogenesis. ${ }^{15-17}$ Recently, it has been reported that TLR7 affects lipid accumulation in hepatocytes by controlling autophagy and lipid peroxidation. ${ }^{18}$ However, it is currently unclear what mechanisms regulate steatohepatitis by TLR7 signaling in vivo.

Therefore, the objective of this study was to clarify the role of TLR7 in the pathogenesis of NASH. We fed the MCD diet to mice to induce experimental NASH because of the reproducibility of this well-established model, which allows the assessment of inflammatory pathway. ${ }^{19-21}$ Our data indicate that TLR7 signaling mediated TNF- $\alpha$ and type 1 interferon (IFN) production in Kupffer cells (KCs) and dendritic cells (DCs), respectively, subsequently suppressing regulatory $\mathrm{T}$ (Treg) cells and leading to steatohepatitis.

\section{Materials and Methods}

\section{Animals and Experimental Protocol}

In the current study, TLR7 knockout (KO) mice, type 1 IFN receptor (IFNAR1) KO mice, depletion of regulatory $\mathrm{T}$ cells (DEREG) mice, and C57BL/6 littermate controls (eight to nine weeks of age, 25 to $30 \mathrm{~g}$ of weight) were used. TLR7-deficient mice were kindly provided by Dr. Shizou Akira (Osaka University, Suita, Japan). IFNAR1 KO mice were purchased from B\&K Universal Limited (Hull, UK) and backcrossed with C57BL/6 mice for at least 10 generations. DEREG mice were provided by Dr. Tim Sparwasser (Technische Universität München, Munich, Germany). ${ }^{22}$ CD11c-DTR transgenic mice were purchased from the Jackson Laboratory (Bar Harbor, ME). These mice received humane care according to US National Institutes of Health recommendations outlined in the Guide for the Care and Use of Laboratory Animals. ${ }^{23}$ Experimental and animal management procedures were undertaken in accordance with requirements from the Animal Care and Ethics Committees of Chonbuk National University.

Mice were used to prepare two different NASH models: acute and chronic. For the acute model, TLR7 KO, IFNAR1 $\mathrm{KO}$, and WT mice ( $n=6$ mice per group) were fed an MCD or methionine-choline-sufficient (MCS) diet (Dyets Inc., Bethlehem, PA) for 17 days. For the chronic model, TLR7 KO, IFNAR1 KO, DEREG, and WT mice $(n=10$ mice per group) were fed an MCD diet for six weeks, an established protocol to prepare NASH model. ${ }^{24}$ After establishing the short-term NASH model, mice were intraperitoneally injected with a single dose of R848 $(2.5 \mathrm{mg} / \mathrm{kg}$, Invivogen, San Diego, CA) or normal saline. At 6 hours after injection, mice were sacrificed to obtain serum samples and liver tissues. Pentoxifylline $(100 \mathrm{mg} / \mathrm{kg}$, Sigma-Aldrich Co., St. Louis, $\mathrm{MO}$ ), an inhibitor of TNF- $\alpha$ production, was intraperitoneally injected at 1 hour and 24 hours before R848 treatment.

\section{Histopathologic Analysis}

For histologic review of hematoxylin and eosin-stained liver sections by light microscopy (BX-51, Olympus Corp., Tokyo, Japan), liver tissues were collected, fixed in $10 \%$ neutral buffered formalin solution for 48 hours, routinely processed, and then embedded in paraffin. Tissue sections (4 $\mu \mathrm{m}$ in thickness) were prepared using a microtome (HM-340E, Thermo Fisher Scientific Inc., Waltham, MA) and placed on glass slides. Hematoxylin and eosin staining was performed according to standard techniques. The NAFLD score was determined by two pathologists independently (Y.S.R. and B.K.) as described previously. ${ }^{25}$

\section{TUNEL Assay}

Terminal deoxynucleotidyl transferase-mediated dUTP nickend labeling (TUNEL) assay was performed on paraffinembedded sections using an ApopTaq Peroxidase in situ apoptosis detection kit (Chemicon, Temecula, CA) according to the manufacturer's instructions. Positive reactions were visualized with $3,3^{\prime}$-diaminobenzidine substrate. Next, nuclear counterstaining was performed using methyl green dye. TUNEL-labeled cells were quantified by the percentage of positive area in high-power field. A total of 10 high-power fields of liver tissues were analyzed for each animal. Data are expressed as percentages of TUNEL-positive areas. Total liver section images were analyzed using a light microscope (BX-51, Olympus Corp.) and digital image software (analySIS TS Auto version 5.1, Olympus Corp.).

\section{Biochemical Measurements}

Serum levels of alanine aminotransferase (ALT) and aspartate aminotransferase (AST) were determined using AM101-K spectrophotometric assay kits (ASAN Pharmaceutical, Hwasung, Korea). Triglyceride and total cholesterol contents in the liver were determined using an AM202-K spectrophotometric assay kit (ASAN Pharmaceutical, Hwasung, Korea).

\section{Real-Time Quantitative RT-PCR}

Total RNA was isolated from liver tissue using Easy-Spin Total RNA extraction kit (iNtRon Biotech, Seoul, Korea). After incubation with RNase-free DNase I (Promega, Madison, WI), reverse transcription was performed using a random 
primer and MultiScribe MuLV Reverse Transcriptase (Applied Biosystems, Foster City, CA) according to the manufacturer's instructions. cDNA was subjected to real-time PCR on a CFX96 Real-Time PCR Detection System (Bio-Rad Laboratories, Hercules, CA) using SYBR Green I as a dye for binding double-strand DNA. All PCR primers were obtained from Bioneer (Daejeon, Korea). After real-time quantitative RT-PCR reaction was completed, specificity was verified by melting curve analysis. Quantification was performed by comparing $\mathrm{Ct}$ values of samples after normalization with glyceraldehyde-3-phosphate dehydrogenase as internal control. Sequences of primers were summarized in Table 1.

\section{Immunoblot Analysis}

Liver tissue was directly lyzed with an extraction buffer (T-PER, Thermo Fisher Scientific Inc.) for 30 minutes on ice. After centrifugation at $13,000 \times g$ for 15 minutes at $4{ }^{\circ} \mathrm{C}$, protein concentration in the supernatant was measured using Bradford's reagent (Thermo Fisher Scientific Inc.). Protein $(30 \mu \mathrm{g})$ was resolved by sodium dodecyl sulfate-polyacrylamide gel electrophoresis on a gradient gel and then transferred onto polyvinylidene difluoride membranes. Blocking was performed using blocking buffer [5\% nonfat dairy milk in Tris-buffered saline $(20 \mathrm{mmol} / \mathrm{L}$ Tris, $150 \mathrm{mmol} / \mathrm{L} \mathrm{NaCl}, \mathrm{pH}$ 7.4) containing $0.05 \%$ Tween20] for 1 hour at room temperature. Primary antibodies were diluted 1:1000 in a blocking buffer and incubated at $4{ }^{\circ} \mathrm{C}$ overnight. The following antibodies were used: antiBcl-2, anti-Bax, and $\beta$-actin (mouse or rabbit antibody, Cell Signaling Technology, Danvers, MA). To detect antigen antibody complexes, anti-rabbit or anti-mouse horseradish peroxidase-conjugated secondary antibodies (Santa Cruz Biotechnology Inc., Santa Cruz, TX) were diluted 1:3000 in blocking buffer and incubated at room temperature for 45 minutes. Immune complexes were visualized using chemiluminescent substrate (Millipore, Burlington, MA) and Kodak X-OMAT film (Eastman Kodak, Rochester, NY) according to the manufacturer's instructions.

\section{Measurement of Thiobarbituric Acid-Reactive Substances and Plasma TNF- $\alpha$}

Hepatic thiobarbituric acid-reactive substances (TBARSs) as oxidative stress markers were measured using a Lab
Assay TBARS kit (Wako Pure Chemical Industries, Osaka, Japan) according to the manufacturer's instructions. Plasma concentration of mouse TNF- $\alpha$ was measured by enzymelink immunosorbent assay using a Quantikine kit (R\&D Systems, Minneapolis, MN) according to the manufacturer's instructions.

\section{Isolation of Hepatocytes and NPCs}

To isolate hepatocytes and hepatic nonparenchymal cells (NPCs), livers of MCS or MCD-fed WT mice, TLR7 KO mice, and IFNAR1 KO mice were perfused $(1 \mathrm{~mL}$ per minute) and digested with collagenase 1 (Worthington Biochemical Corporation, Lakewood, NJ) after cannulation of portal vein. Liver cell suspension was centrifuged at $50 \times$ $g$ for 3 minutes. After centrifugation, the pellet representing hepatocytes was resuspended, filtered, and washed several times using Dulbecco's modified Eagle's medium (PAA Laboratories, Piscataway, NJ) supplemented with 5\% fetal bovine serum (Thermo Fisher Scientific Inc.), $100 \mathrm{nmol} / \mathrm{L}$ dexamethasone (Sigma-Aldrich), 1\% insulin-transferrinselenium-X supplement (Thermo Fisher Scientific Inc.), $100 \mathrm{IU} / \mathrm{mL}$ of penicillin, and $100 \mu \mathrm{g} / \mathrm{mL}$ of streptomycin. Viability of hepatocytes was assessed using trypan blue (Sigma-Aldrich).

After centrifuging digested liver cell suspension at $50 \times g$ for 3 minutes, the supernatant containing hepatic NPCs was collected, washed with phosphate-buffered saline, and resuspended in 40\% Percoll in RPMI 1640 media. The cell suspension was gently overlaid onto $70 \%$ Percoll and centrifuged at $750 \times g$ for 20 minutes with off-brake setting. NPCs were collected from the interface, washed twice with phosphate-buffered saline, and resuspended in RPMI 1640 media.

\section{Cell Culture}

Murine normal hepatocyte cell line TIB-73 was obtained from the ATCC (Manassas, VA). Murine monocyte/macrophage cell line RAW 264.7 was obtained from the ATCC. These cells were cultured at $37^{\circ} \mathrm{C}$ under $5 \% \mathrm{CO}_{2}$ in Dulbecco's modified Eagle's medium (PAA Laboratories) supplemented with $10 \%$ fetal bovine serum, $4 \mathrm{mmol} /$ L L-glutamine (PAA Laboratories), $100 \mathrm{IU} / \mathrm{mL}$ of penicillin, and $100 \mu \mathrm{g} / \mathrm{mL}$ of streptomycin.

Table 1 Sequences of Primers Used for Real-Time PCR

\begin{tabular}{|c|c|c|}
\hline Gene & Forward & Reverse \\
\hline Tnfa & 5'-TСТАСТСССАGGTTCTCTTCAAGG-3' & 5'-GCAAATCGGCTGACGGTGTG-3' \\
\hline Foxp3 & $5^{\prime}$-GGAGAGGCAGAGGACACTCAATG- $3^{\prime}$ & 5'-TCAGGTTGTGGCGGATGGC- $3^{\prime}$ \\
\hline Lpl & $5^{\prime}-\mathrm{TCTGTACGGCACAGTGG-3^{ \prime }}$ & 5'-CCTCTCGATGACGAAGC- $3^{\prime}$ \\
\hline Fabp1 & $5^{\prime}-$ TGGACCCAAAGTGGTCCGCA-3' & 5'-AGTTCAGTCACGGACTTTAT-3' \\
\hline Pparg & 5'-CGGAAGCCCTTTGGTGACTTTATG-3' & 5'-GCAGCAGGTTGTCTTGGATGTC-3' \\
\hline
\end{tabular}


For co-culture experiments, primary hepatocytes and NPCs isolated from WT mice, TLR7 KO mice, and IFNAR1 KO mice were co-cultured in collagen-coated 12well Transwell plate (Sigma-Aldrich) with or without $0.4 \mathrm{mmol} / \mathrm{L}$ palmitic acid for 24 hours. Hepatocyte death was evaluated using a cytotoxicity detection kit (SigmaAldrich) based on the measurement of activity of lactate dehydrogenase released from the cytosol into the culture medium following the manufacturer's instruction. Absorbance of sample was measured at wavelength of $490 \mathrm{~nm}$ using an EMax spectrophotometer (Molecular Devices, Sunnyvale, CA).

\section{Quantification of Cell Death Induced by $\mathrm{H}_{2} \mathrm{O}_{2}$ and TNF- $\alpha$}

Cell Counting Kit-8 (Dojindo Molecular Technologies Inc., Rockville, MD) was used to detect cellular activity of dehydrogenase, a well-known hallmark of viability. A total of $2.5 \times 10^{4}$ primary hepatocytes per well were plated onto a 48-well collagen-coated plate in duplicates and incubated overnight. These cells were then treated with 0,20 , or $100 \mu \mathrm{mol} / \mathrm{L} \mathrm{H}_{2} \mathrm{O}_{2}$ for 5 minutes. After that, $20 \mathrm{ng} / \mathrm{mL}$ of TNF- $\alpha$ was added into each well. After incubating for 16 hours at $37^{\circ} \mathrm{C}$, samples were assayed according to the manufacturer's instructions.

\section{Phosphorothioate IRS Oligodeoxyribonucleotides Synthesis and Antagonist of TLR7}

The following endotoxin-free oligodeoxyribonucleotides (ODNs, Bioneer) were used for in vitro or in vivo studies: immunoregulatory sequence (IRS) 661, 5'-TGCTTGCAAGCTTGCAAGCA-3', and control ODNs, 5'-TCCTGCAGGTTAAGT- $3^{\prime}$. Various groups of mice were treated with saline, IRS 661, or control ODN at dose of $50 \mu \mathrm{g}$ on alternate days during the MCD diet.

\section{Flow Cytometric Analysis}

Hepatic NPCs obtained from livers were stained with fluorescein isothiocyanate anti-CD4 antibody and allophycocyanin anti-CD25 antibody (e-Biosciences, San Diego, CA) on ice for 30 minutes followed by fixation with permeabilization concentrate buffer (e-Biosciences) at $4^{\circ} \mathrm{C}$ for 6 hours. After fixation, cells were washed twice with permeabilization buffer and stained with phosphatidylethanolamine anti-Foxp3 antibody in permeabilization buffer at room temperature for 30 minutes. For detection of early and late apoptosis, the liver NPCs were stained with anti-CD4 antibody and anti-CD25 antibody and washed with phosphate-buffered saline. Then, cells were suspended in binding buffer and supplemented with annexin $\mathrm{V}(\mathrm{AV})$ and propidium iodide (PI) for 15 minutes at room temperature without light exposure. The cells with fluorescence $\mathrm{AV}^{+} / \mathrm{PI}^{-}$were considered to be early apoptotic cells, and those with fluorescence $\mathrm{AV}^{+} / \mathrm{PI}^{+}$ were considered to be late apoptotic cells. Data were analyzed using CellQuest software version 3.1 (BD Biosciences, Franklin Lakes, NJ) or FlowJo software version 7.8 (FlowJo, Ashland, OR).

\section{Statistical Analysis}

All data are expressed as means \pm SEM. Differences between the two groups were compared using a two-tailed $t$-test. Statistically significant difference between groups was considered at $P<0.05$. All Western blotting, real-time quantitative RT-PCR, flow cytometry, and immunocytochemistry experiments were repeated at least twice with five to 10 different mice or samples per group. Only representative results are shown in the figures.

\section{Results}

\section{TLR7 Deficient Mice Are Resistant to NASH}

To investigate the role of TLR7 in the pathogenesis of NASH, WT and TLR7-deficient mice were fed with an MCD or MCS diet (control) for 6 weeks. After feeding with an MCD diet, livers of WT mice had marked lipid accumulation with infiltration of inflammatory cells. In contrast, livers of TLR7-deficient mice had significant reduction of steatosis and inflammation compared with those of WT mice (Figure 1A). NAFLD activity scores as determined by the degree of steatosis and inflammation ${ }^{25}$ were significantly lower in TLR7-deficient mice than that in WT mice (Figure 1A). Reduced liver injury in TLR7deficient mice was confirmed by lower serum ALT and AST levels (Figure 1B). Several lines of evidence have indicated that adiponectin and peroxisome proliferatoractivated receptor gamma (PPAR $\gamma$ ) can negatively regulate the severity of NASH. ${ }^{26-28}$ To understand how TLR7 signaling might regulate lipid accumulation, expression levels of PPAR $\gamma$ and PPAR $\gamma$-dependent target genes (LFABP and LPL) ${ }^{26,29}$ were examined in livers of WT and TLR7-deficient mice fed with an MCD diet. Expression levels of PPAR $\gamma$, LFABP, and LPL in TLR7deficient mice fed with an MCD diet were significantly higher than those in WT mice fed with the same diet (Figure 1C). Moreover, expression level of adiponectin, an anti-inflammatory adipokine, was up-regulated in livers of TLR7-deficient mice fed with an MCD diet compared with that in WT mice fed with the same diet (Figure 1C). These results suggest that TLR7 signaling is involved in the progression of NASH.

\section{TLR7-Induced TNF- $\alpha$ Promotes Hepatocyte Damage}

To demonstrate the mechanistic effects of the TLR7-type I IFN pathway on steatotic hepatocyte death, ex vivo experiments were conducted using a hepatocytes-KCs coculture system. Viabilities of WT and TLR7-deficient hepatocytes 
A

WT

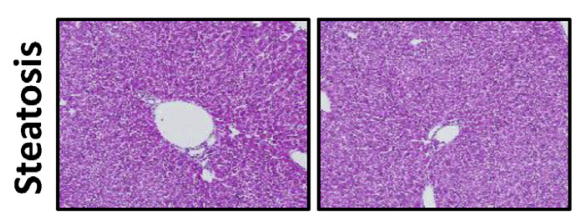

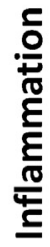

B
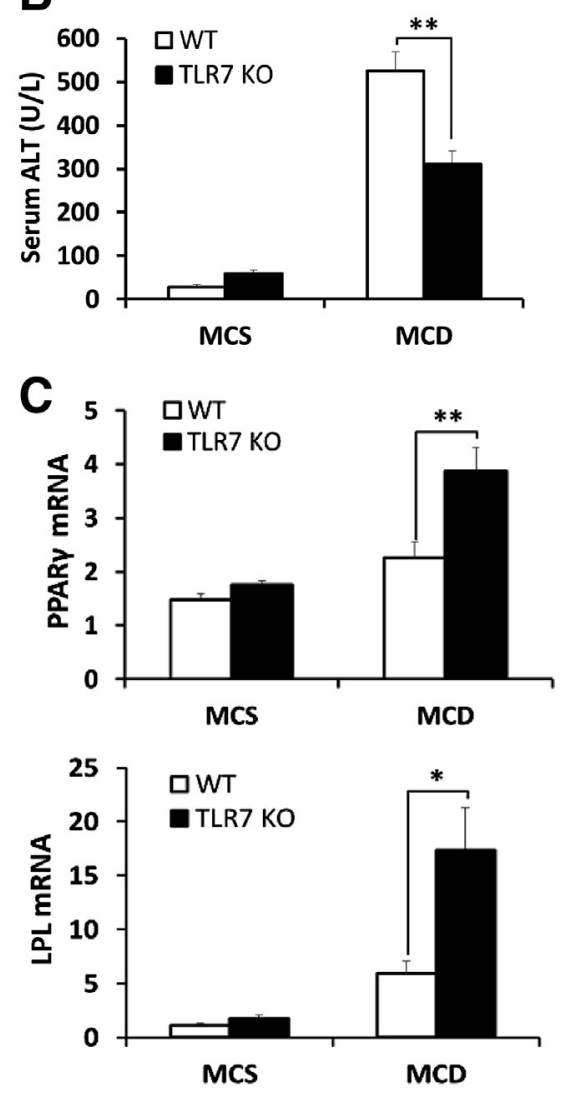

WT
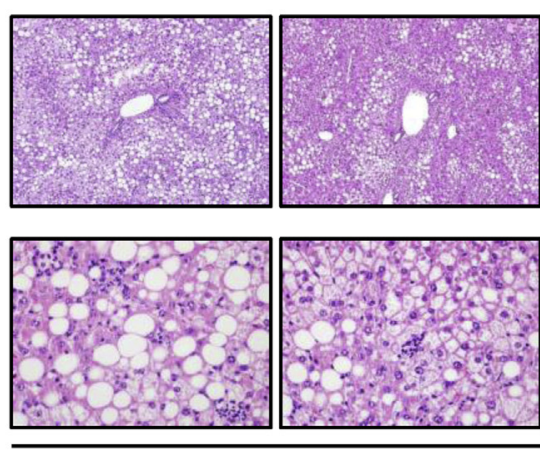

MCD
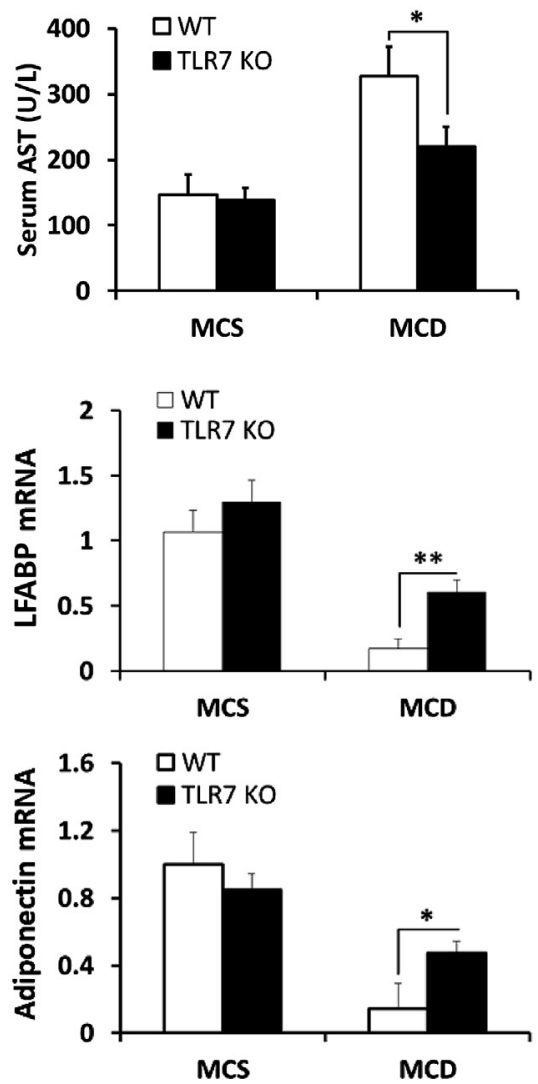

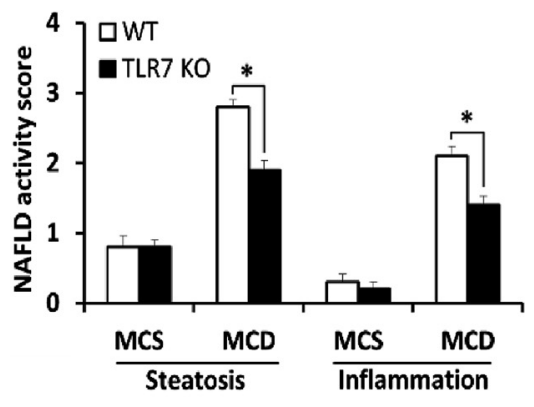

Figure 1 Toll-like receptor7 (TLR7)-deficient mice are resistant to methionine-choline-deficient (MCD) diet-induced hepatocyte damage and inflammation. Wild-type (WT) and TLR7-deficient mice were fed a methioninecholine-sufficient (MCS) or MCD diet for 6 weeks. A: Liver sections stained with hematoxylin and eosin to assess steatosis and inflammation. Nonalcoholic fatty liver disease (NAFLD) activity scores were calculated based on histologic evaluation of steatosis and inflammation. B: Serum levels of alanine aminotransferase (ALT) and aspartate aminotransferase (AST). C: Hepatic mRNA levels of peroxisome proliferator-activated receptor gamma (PPAR $\gamma$ ), LFABP, LPL, and adiponectin determined by real-time quantitative RT-PCR. They are shown as fold changes compared with those in the MCS-fed WT mice. Data are expressed as means \pm SEM per group. $n=6$ mice in the MCS group; $n=8$ mice in the MCD group. ${ }^{*} P<0.05,{ }^{* *} P<0.01$ (two-tailed $t$-test). $\mathrm{K} 0$, knockout. Original magnification: $\times 100($ A, top row); $\times 400$ (A, bottom row). were comparable after treatment with palmitic acid (Supplemental Figure S1A). To mimic in vivo condition, hepatocytes were co-cultured with KCs. Hepatocytes co-cultured with KCs from livers of TLR7-deficient mice had significantly less cell death compared with those from livers of WT mice (Figure 2A). In contrast, these effects were dampened in the presence of TNF- $\alpha$ (Figure 2B). Furthermore, R848-induced cell death was significantly inhibited by pentoxifylline treatment, suggesting that TLR7mediated hepatocyte death is dependent on $\mathrm{KC}$-derived TNF- $\alpha$ (Figure 2C). Consistently, the expression of TNF$\alpha$ was significantly decreased in TLR7-deficient mice fed with an MCD diet. The expression level of TNF- $\alpha$ was markedly down-regulated in co-cultured TLR7 KO KCs compared with that in WT KCs (Figure 2D), suggesting that $\mathrm{KCs}$ might be the major source for inducing TNF$\alpha$-mediated hepatocyte death. R848 treatment dramatically up-regulated hepatic mRNA expression of TNF- $\alpha$ in MCDfed mice compared with that in MCS-fed mice (Supplemental Figure S1, B and C). The serum ALT level was also significantly increased by $\mathrm{R} 848$ treatment in both diet groups (Figure 2E), which was corroborated by the results of hepatocyte apoptosis using TUNEL results (Supplemental Figure S2, A and B). These results indicate that TNF- $\alpha$ might be a key mediator in the pathogenesis of lipid-mediated hepatocyte death. 

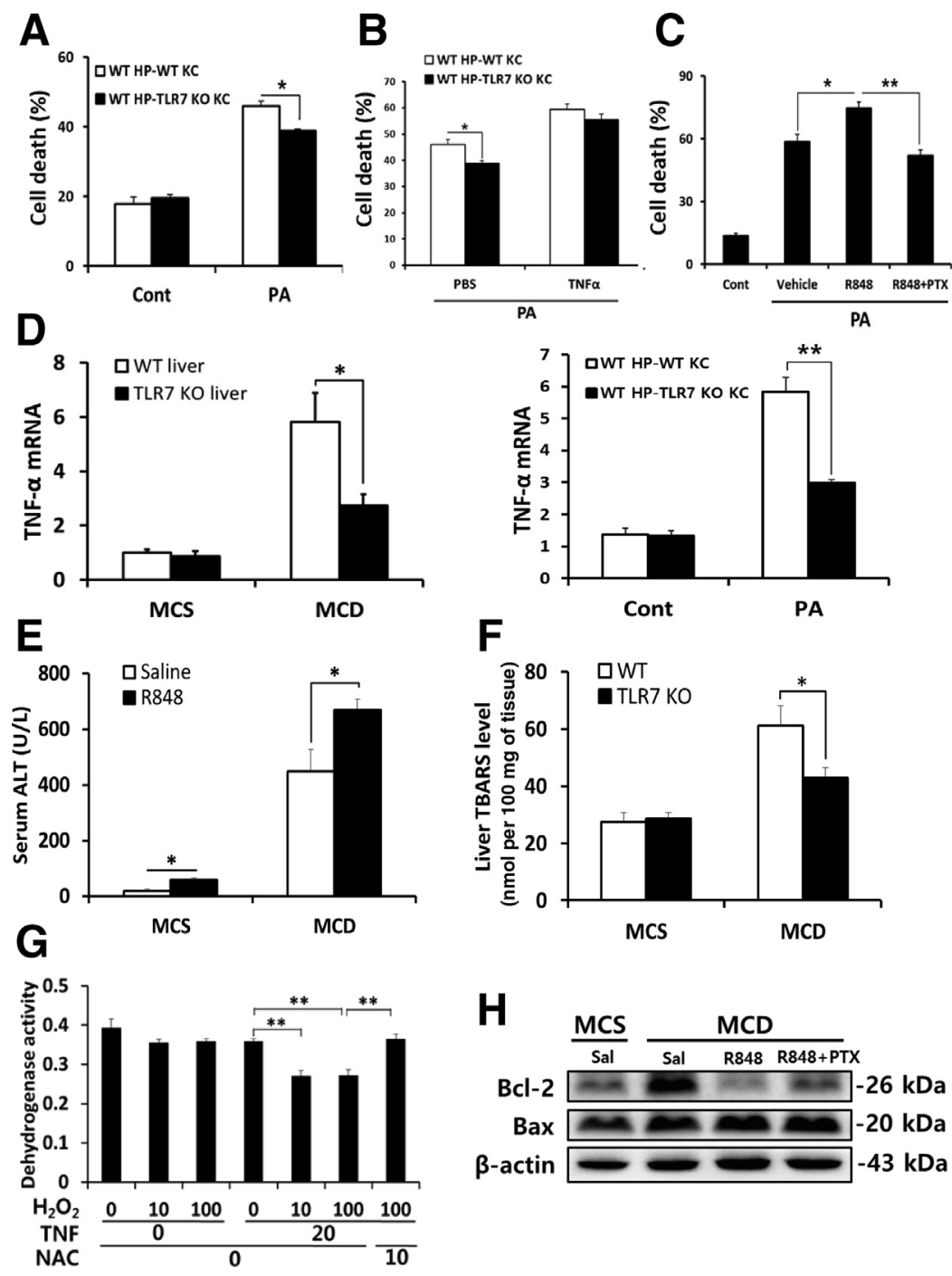

H

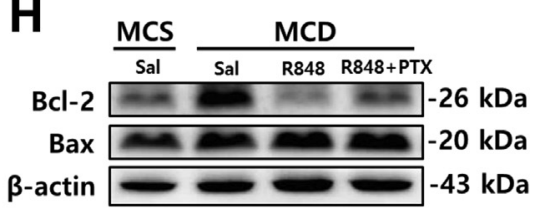

Figure 2 Toll-like receptor 7 (TLR7)-induced tumor necrosis factor (TNF)- $\alpha$ promotes hepatocyte damage. A: Hepatocyte death in palmitic acid (PA)-treated primary hepatocytes co-cultured with Kupffer cells (KCs) from livers of hepatic (HP) wild-type (WT) and TLR7-deficient mice. B: Hepatocyte death in PA-treated primary hepatocytes cocultured with KCs from livers of HP WT and TLR7-deficient mice in the presence of phosphate-buffered saline (PBS) or TNF- $\alpha$. C: Hepatocyte death in PA-treated primary hepatocytes co-cultured with KCs from livers of HP WT and TLR7-deficient mice in the presence of R848 or pentoxifylline (PTX). D: The mRNA expression of TNF- $\alpha$ in liver and KCs determined by real-time quantitative RT-PCR. It is shown as fold change compared with that in methionine-cholinesufficient (MCS) diet-fed WT mice or control WT nonparenchymal cells. E: Serum alanine aminotransferase (ALT) levels. F: Amounts of HP thiobarbituric acid-reactive substances (TBARSs) in MCS or methionine-choline-deficient (MCD) diet-fed WT and TLR7-deficient mice. G: Hepatocyte death using cell death detection assay kit after 16 hours of incubation with TNF- $\alpha$. TIB-73 hepatocytes were pretreated with $\mathrm{H}_{2} \mathrm{O}_{2}(0,10,100 \mu \mathrm{mol} / \mathrm{L})$ for 5 minutes before stimulation with $20 \mathrm{ng} / \mathrm{mL}$ of TNF- $\alpha$. N-acetylcysteine (NAC) $(10 \mathrm{mmol} / \mathrm{L})$ was added for 30 minutes before $\mathrm{H}_{2} \mathrm{O}_{2}$ treatment. H: Protein expression of $\mathrm{Bcl}-2, \mathrm{Bax}$, and $\beta$-actin measured by Western blot analysis. Samples were obtained 6 hours after R848 or PTX injection in MCD diet- or MCS dietfed WT mice (feeding for 17 days). Data are expressed as means \pm SEM per group. ${ }^{*} P<0.05,{ }^{* *} P<0.01$ (two-tailed $t$-test). Cont, control; KO, knockout; Sal, saline.
Oxidative stress is known to play an important role in the pathogenesis of NASH. ${ }^{9,14,30}$ Therefore, lipid peroxidation was assessed by quantifying levels of TBARSs, a major indicator of oxidative stress. ${ }^{31}$ As expected, TBARS levels were increased in the MCD diet group compared with those in the MCS diet group. However, WT mice had significant higher levels of TBARSs than TLR7-deficient mice (Figure 2F). Of note, reactive oxygen species and R848 synergistically induced TNF- $\alpha$ production in macrophages (Supplemental Figures S3 and S4). To access the contribution of reactive oxygen species and TNF- $\alpha$ to hepatocyte apoptosis, cultured hepatocytes were incubated with $\mathrm{H}_{2} \mathrm{O}_{2}$ and TNF- $\alpha$. Neither $\mathrm{H}_{2} \mathrm{O}_{2}$ nor TNF- $\alpha$ treatment alone significantly increased apoptosis of hepatocytes, although TNF- $\alpha$ treatment slightly enhanced apoptosis of hepatocytes. Pretreatment with $\mathrm{H}_{2} \mathrm{O}_{2}$ synergistically enhanced TNF$\alpha$-induced hepatocyte apoptosis compared with untreated cells, whereas pretreatment with $\mathrm{N}$-acetylcysteine significantly suppressed apoptosis induced by co-treatment with
$\mathrm{H}_{2} \mathrm{O}_{2}$ and TNF- $\alpha$ (Figure $2 \mathrm{G}$ ). The Bcl-2 family protein is known as the key upstream signal for TNF- $\alpha$-induced apoptosis. ${ }^{32}$ Therefore, expression levels of Bcl-2 and Bax were evaluated by Western blot analysis to elucidate the cell death machinery in hepatocytes induced by R848. R848 decreased the expression level of $\mathrm{Bcl}-2$, an antiapoptotic protein, in whole lysate of the liver without changing the expression level of Bax, a proapoptotic protein. Of interest, pentoxifylline, an inhibitor of TNF- $\alpha$ production, ${ }^{33}$ partially restored the reduction in $\mathrm{Bcl}-2$ expression caused by $\mathrm{R} 848$ treatment (Figure $2 \mathrm{H}$ ). Collectively, our results suggest that TLR7-induced hepatocyte apoptosis and steatohepatitis are dependent on TNF- $\alpha-$ mediated mechanism.

\section{TLR7-Type I IFN Axis Is Required for Lipid-Laden Hepatocyte Death}

TLR7 signaling is transduced by two cascades, the NF- $\kappa \mathrm{B}$ and interferon regulatory factor 7 pathways, that can induce 

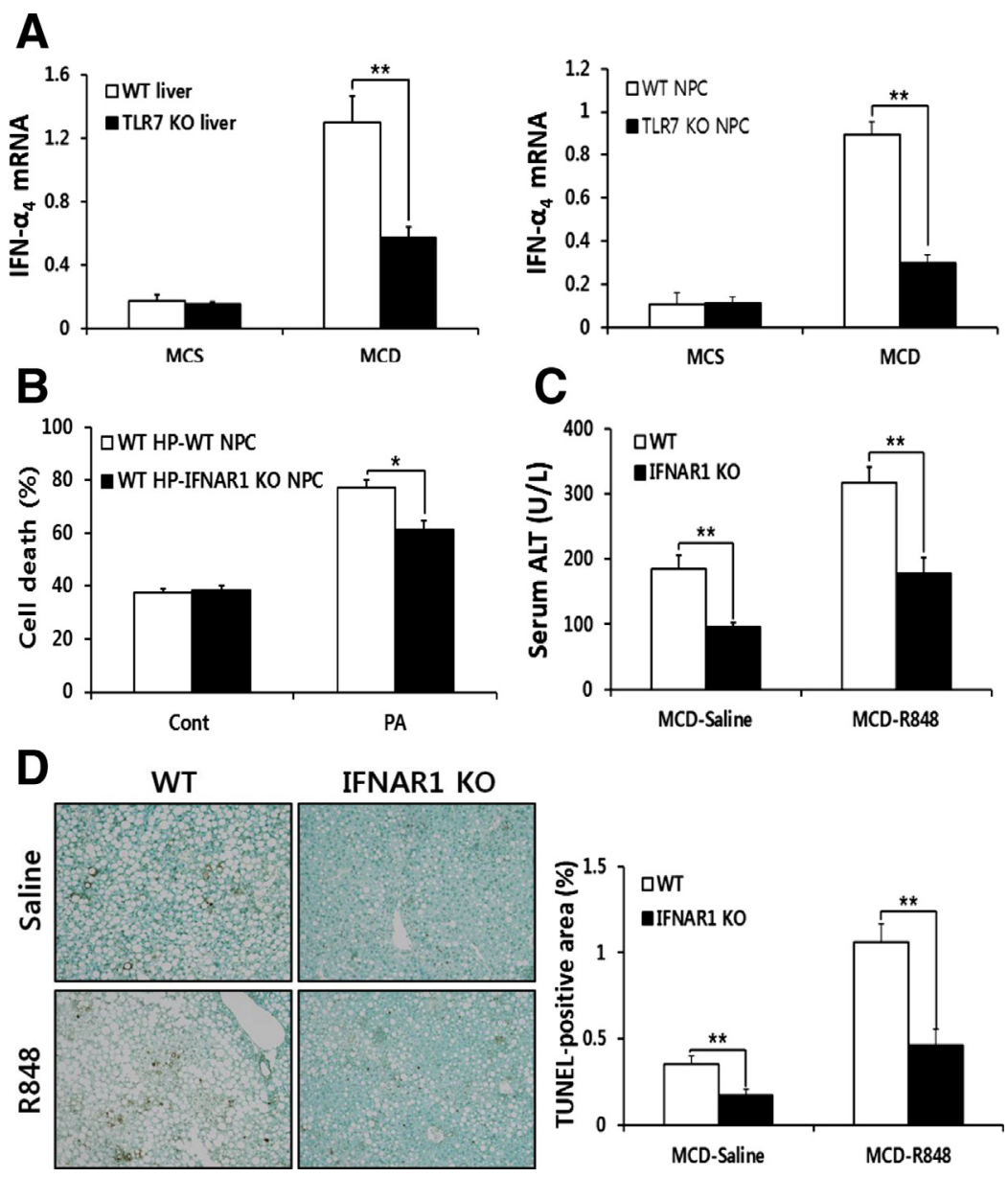
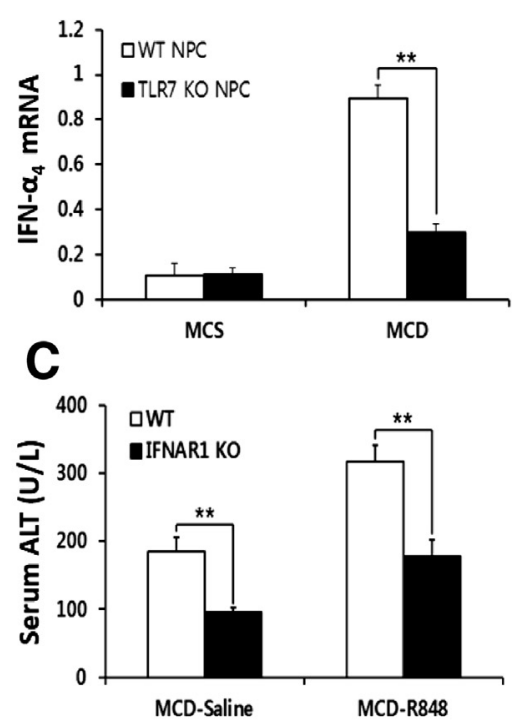

Figure 3 Toll-like receptor 7 (TLR7)-type I interferon (IFN) axis is required for lipid-laden hepatocyte death. A: The mRNA expression of IFN- $\alpha_{4}$ in liver and nonparenchymal cells (NPCs) determined by real-time quantitative RT-PCR and shown as fold change compared with that in methionine-choline-sufficient (MCS)-fed wild-type (WT) mice. B: Hepatocyte death measured in palmitic acid (PA) $(400 \mu \mathrm{mol} / \mathrm{L})$-treated primary hepatocytes co-cultured with NPCs from WT and IFN- $\alpha / \beta$ receptor 1 (IFNAR1)-deficient liver. C: Serum alanine aminotransferase (ALT) levels measured in R848-treated WT and IFNAR1-deficient mice. D: Apoptosis determined by terminal deoxynucleotidyl transferase-mediated dUTP nick-end labeling (TUNEL) staining and quantification of TUNEL-positive area. Data are expressed as means \pm SEM per group. ${ }^{*} P<0.05,{ }^{*} * P<0.01$ (two-tailed $t$-test). Original magnification: $\times 100$ (D). Cont, control; K0, knockout; HP, hepatic; MCD, methionine-cholinedeficient. the production of proinflammatory cytokines TNF- $\alpha$ and type I IFN, respectively. ${ }^{34,35}$ Therefore, the expression levels of IFN- $\alpha_{4}$ were examined in liver and NPCs known to be able to produce type I IFN. ${ }^{36}$ As expected, expression levels of IFN- $\alpha_{4}$ were increased in livers or NPCs of MCDfed mice. Such increases were considerably decreased in MCD-fed mice that lacked TLR7 (Figure 3A). These results prompted us to test whether the TLR7-type I IFN pathway affected hepatocellular damage. Palmitic acid-induced hepatotoxicity was significantly down-regulated in cocultured IFNAR1 KO NPCs compared with that in WT NPCs (Figure 3B), suggesting that NPCs might be the major source for the induction of type I IFN-mediated hepatocyte death. Consistent with results of ex vivo studies, liver injury was markedly decreased in MCD-fed IFNAR1 KO mice compared with that in MCD-fed WT mice based on reduced levels of serum ALT in the presence or absence of R848 administration (Figure 3C). Furthermore, hepatocyte damage induced by $\mathrm{R} 848$ treatment was reduced in MCD-fed IFNAR1 KO mice compared with that in MCD-fed WT mice based on TUNEL staining (Figure 3D). Taken together, our findings indicate that TLR7-dependent type I IFN is responsible for the progression of liver injury in NASH development.

\section{Decreased Type I IFN in TLR7-Deficient Mice Contributes to Protection against NASH}

To further verify the role of type I IFN in downstream pathway of TLR7 in NASH, NASH was examined in WT and IFNAR1-deficient mice. Similar to the findings in TLR7 KO mice, livers of IFNAR1 KO mice had a significant reduction of steatosis and inflammation compared with those of WT mice (Figure 4A). The NAFLD activity scores as determined by the degree of steatosis and inflammation $^{25}$ were also significantly lower in IFNAR1 KO mice than that in WT mice (Figure 4A). Reduced liver injury in IFNAR1 KO mice was confirmed by lower serum ALT and AST levels (Figure 4B). Consistent with these results, livers of IFNAR1 KO mice had significant reductions of inflammation and lipid peroxidation compared with those of WT mice (Figure 4, C and D). Moreover, lower lipid accumulation was observed in livers of MCDfed IFNAR1 KO mice based on higher expression levels of PPAR $\gamma$ and its target genes (Figure 4E). These findings, together with the earlier results (Figures 1, 2, and 3), suggest that ameliorated NASH in TLR7-deficient mice is mediated by the loss of detrimental TNF- $\alpha$ and type I IFN signaling. 

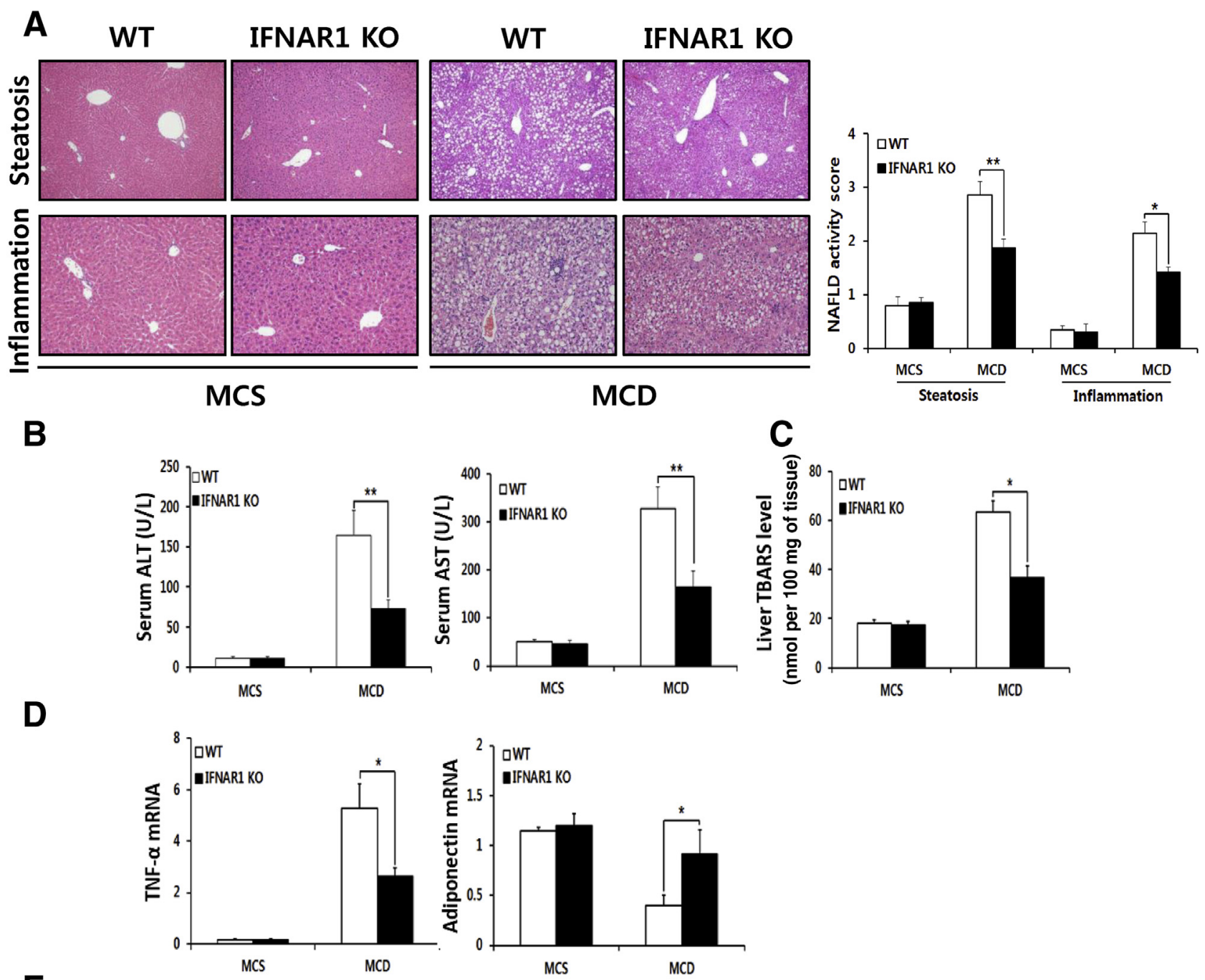

$\mathbf{E}$
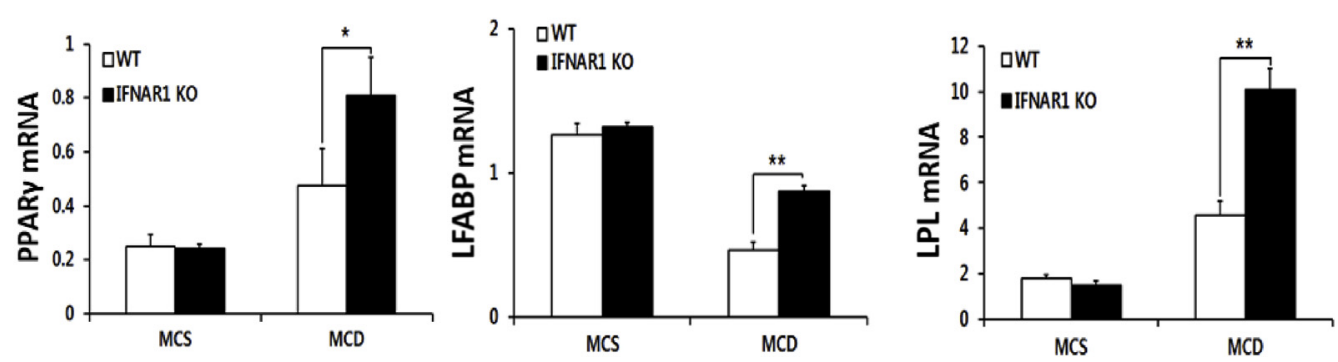

Figure 4 Methionine-choline-deficient (MCD) diet-induced nonalcoholic steatohepatitis is ameliorated in interferon- $\alpha / \beta$ receptor 1 (IFNAR1)-deficient mice. Wild-type (WT) and IFNAR1-deficient mice were fed a methionine-choline-sufficient (MCS) or MCD diet for 6 weeks. A: Liver sections stained with hematoxylin and eosin for assessment of steatosis and inflammation. Nonalcoholic fatty liver disease (NAFLD) activity scores were calculated based on histologic evaluation of steatosis and inflammation. B: Serum levels of alanine aminotransferase (ALT) and aspartate aminotransferase (AST). C: Amounts of hepatic thiobarbituric acid-reactive substances (TBARSs) measured in MCS diet- or MCD diet-fed WT and IFNAR1-deficient mice. D: Hepatic mRNA expression levels of adipokines (TNF- $\alpha$ and adiponectin) determined by real-time quantitative RT-PCR shown as fold change compared with those in MCS diet-fed WT mice. E: Hepatic mRNA levels of peroxisome proliferator-activated receptor gamma (PPAR $)$, LFABP, and LPL determined by real-time quantitative RT-PCR shown as fold change compared to those in MCS-fed WT mice. Data are expressed as means \pm SEM per group. $n=6$ mice in the MCS group; $n=8$ mice in the MCD group. ${ }^{*} P<0.05,{ }^{*} P<<0.01$ (two-tailed $t$-test). Original magnification: $\times 100$ (A, top row); $\times 200$ (A, bottom row). K0, knockout.

\section{TLR7-Induced Type I IFN and TNF- $\alpha$ Promotes Apoptosis of Treg Cells}

The pathologic effect of TLR7 signaling against NASH implied the involvement of TNF- $\alpha$ or type I IFN-dependent immune regulatory factors. Therefore, the expression level of another TLR7-dependent factor, Foxp3, a crucial transcription factor for Treg cell activation, was examined. Hepatic Foxp $3^{+}$Treg cell population in NASH liver was significantly increased in both TLR7- and IFNAR1-deficient 
mice compared with that in WT mice (Figure 5, A and B). To identify the responsible cell type for regulating Treg cells on TLR7 activation, R848 was administered to CD11cdiptheria toxin (DT) receptor transgenic mice after depletion of DCs by DT injection or to WT mice after depletion of KCs by clodronate liposome injection. According to a previous publication $^{36}$ and Supplemental Figure S5, the depletion of DCs or KCs significantly reduced the production of type I IFN and TNF- $\alpha$, respectively. Of interest, TLR7 activation by R848 significantly decreased the Foxp3 expression level in the liver. Of note, such reduction was significantly recovered in DC-depleted mice and pentoxifylline-treated WT mice (Figure 5, C and D). Next, the number of hepatic Treg cells were measured after R848 treatment. Consistently, the R848-induced reduction of Foxp $3{ }^{+} \mathrm{CD} 25^{+}$Treg cells was recovered in DC-depleted or pentoxifylline-treated mice (Figure 5E). Likewise, R848-induced reduction of Foxp3 expression was recovered in IFNAR1 KO mice (Figure 5F). These results prompted us to examine whether type I IFN or TNF- $\alpha$ affect viability of intrahepatic Treg cells on TLR7 activation. Indeed, TLR7 activation increased early $\left(\mathrm{AV}^{+} / \mathrm{PI}^{-}\right)$and late $\left(\mathrm{AV}^{+} / \mathrm{PI}^{+}\right)$apoptosis of Treg cells and this induction was reduced by DC depletion or pentoxifylline treatment (Figure 5G). Collectively, these results suggest that TLR7 signaling induces production of type I IFN and TNF- $\alpha$, which in turn promotes apoptosis of Treg cells.

\section{Foxp3 ${ }^{+}$Treg Cells Prevent NASH Development}

On the basis of the results reported in Figure 5, whether Foxp $3^{+}$Treg cells might play a role in the pathogenesis of
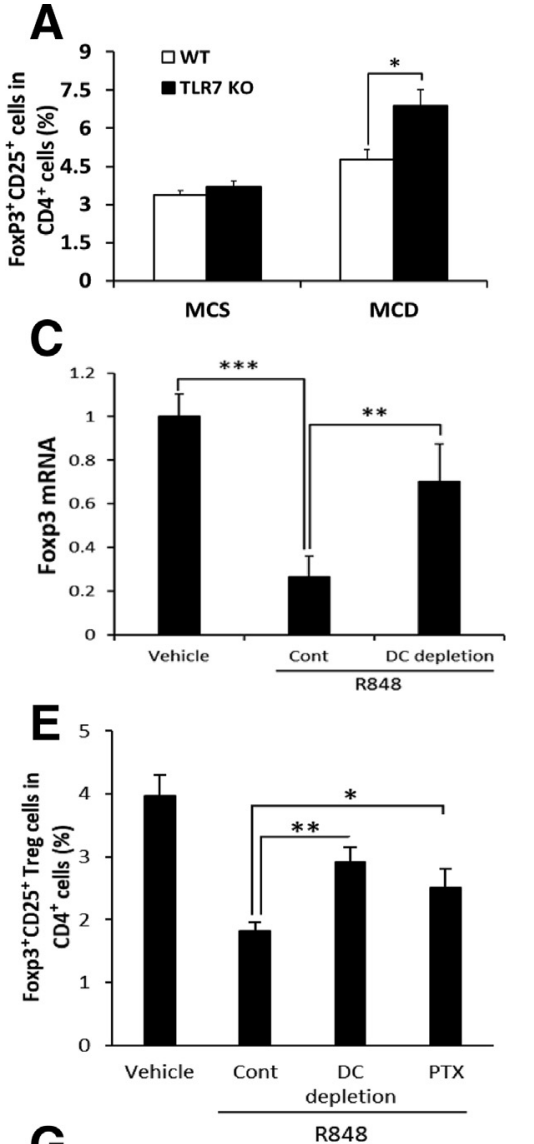

G

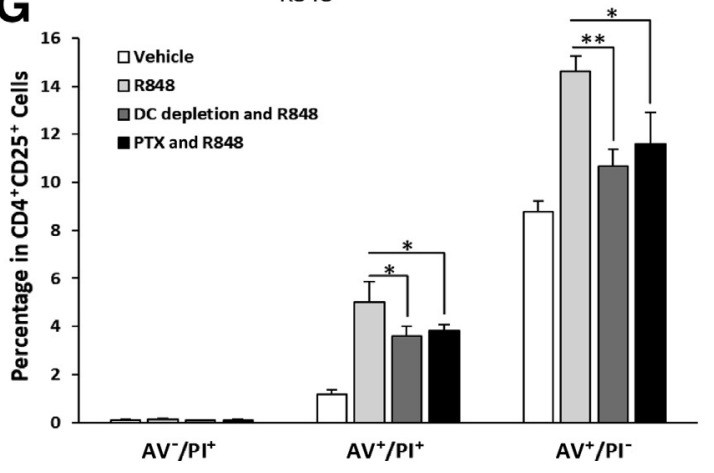

Figure 5 Toll-like receptor 7 (TLR7)-induced type I interferon (IFN) and tumor necrosis factor (TNF)- $\alpha$ promotes apoptosis of $\mathrm{T}$ regulatory (Treg) cells. $\mathbf{A}$ and $\mathbf{B}$ : Hepatic Foxp $3^{+} \mathrm{CD}_{25}{ }^{+} \mathrm{CD}^{+}$cells counted by flow cytometry. Nonparenchymal cells (NPCs) were collected from methionine-choline-sufficient (MCS) - or methioninecholine-deficient (MCD)-fed wild-type (WT), TLR7-, and interferon- $\alpha / \beta$ receptor 1 (IFNAR1)-deficient mice livers after feeding for 6 weeks. C and D: mRNA expression levels of Foxp3 determined by real-time quantitative RT-PCR in WT mice livers at 2 hours after injection of TLR7 ligand (R848). Dendritic cells (DCs) were depleted by diphtheria toxin (DT) injections (2 $\mathrm{ng} / \mathrm{g}$ of body weight) to CD11cDT receptor (DTR) mice for 2 consecutive days. Pentoxifylline (PTX) was used to treat WT mice for a consecutive 2 days. E: Hepatic Foxp $3^{+} \mathrm{CD} 25^{+} \mathrm{CD} 4^{+}$cells counted by flow cytometry. NPCs were collected from DT-treated CD11c-DTR mice or PTX-treated WT mice. F: Foxp3 mRNA expression levels measured by real-time quantitative RTPCR in WT and IFNAR1-deficient mice livers at 2 hours after injection of TLR7 ligand (R848). G: Early and late apoptosis of hepatic $\mathrm{CD}_{4}^{+} \mathrm{CD} 25^{+}$cells were counted by annexin $\mathrm{V}(\mathrm{AV})$ /propidium iodide (PI) staining. Living cells $\left(\mathrm{AV}^{-} / \mathrm{PI}^{-}\right)$; early apoptotic cells $\left(\mathrm{AV}^{+} / \mathrm{PI}^{-}\right)$; late apoptotic cells $\left(\mathrm{AV}^{+} / \mathrm{PI}^{+}\right)$. Data are expressed as means \pm SEM per group. ${ }^{*} P<0.05,{ }^{*} P<<0.01$, and $* * * P<0.001$ (two-tailed $t$-test). Cont, control; K0, knockout. 
NASH was tested. To identify the in vivo role of Foxp $3^{+}$ Treg cells in NASH more specifically, bacterial artificial chromosome transgenic mice (DEREG mice) expressing a DT receptor-green fluorescent protein fusion protein under the control of Foxp3 locus were used. ${ }^{37}$ Histopathologic analysis and NAFLD scoring were performed for livers of MCD-fed DEREG and WT mice. Severe steatohepatitis was observed in mice that lacked Foxp $3^{+}$Treg cells (Figure 6A). Consistent with the severity of NASH, a higher expression level of TNF- $\alpha$ and a lower expression level of adiponectin were detected in DEREG mice compared with those in WT mice (Figure 6B). Expression levels of PPAR $\gamma$ and LFABP but not LPL in DERER mice fed an MCD diet were significantly lower than those in WT mice fed an MCD diet
(Figure 6C). Taken together, these results suggest that Foxp $^{+}$Treg cells have protective role against MCDinduced NASH.

\section{TLR7 Antagonism with IRS 661 Reduces NASH in Vivo}

To test the therapeutic potential of TLR7 signaling in the pathogenesis of NASH, MCD-fed mice were treated with IRS 661, an ODN-based TLR7 antagonist. IRS $661(50 \mu \mathrm{g})$ or control ODN (vehicle) was administered to WT mice twice a week concomitantly with an MCS or MCD diet. Mice treated with IRS 661 had reduced steatosis and inflammation compared with control ODN-treated mice (Figure 7A). The NAFLD score was significantly lower in

\section{A}

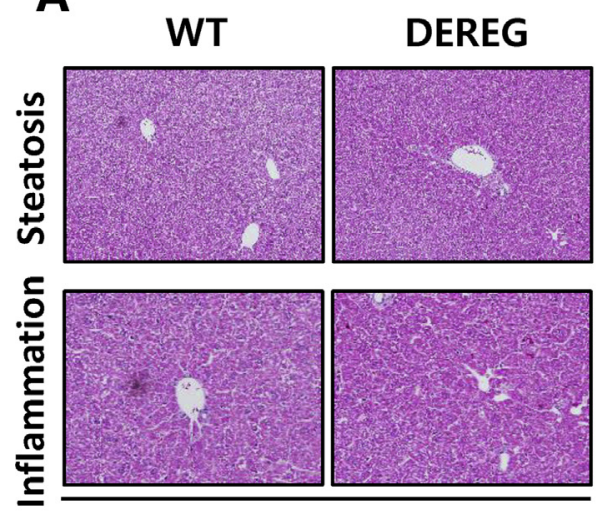

B

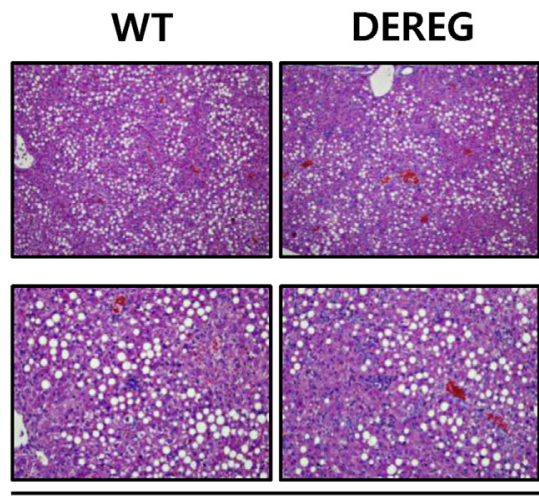

MCD
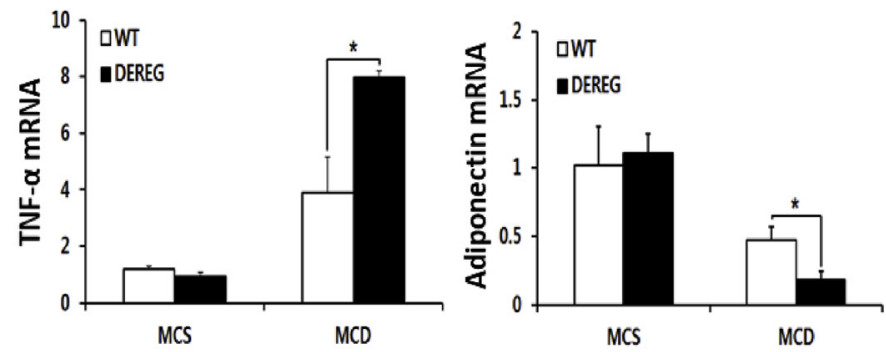

C
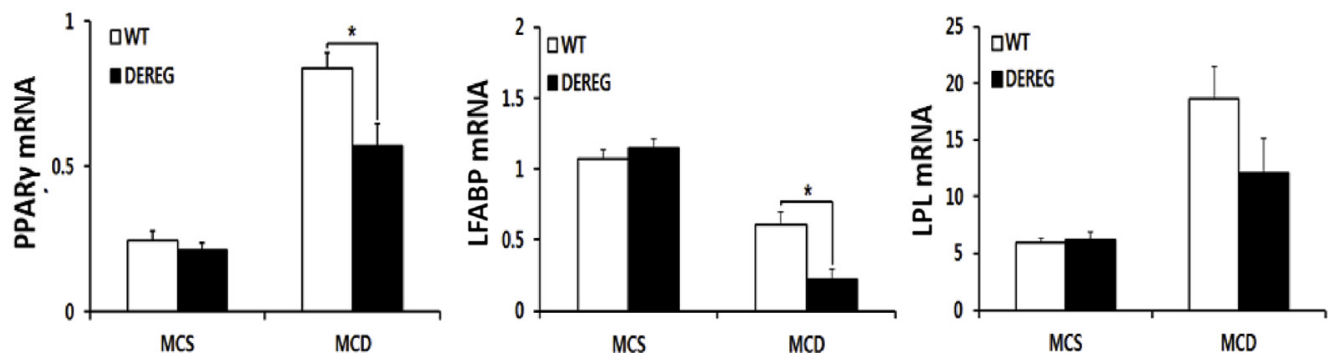

Figure 6 Depletion of hepatic Foxp3 ${ }^{+}$T regulatory (Treg) cells induces more nonalcoholic steatohepatitis. Wild-type (WT) and Treg cell-depleted (DEREG) mice were fed a methionine-choline-sufficient (MCS) or methionine-choline-deficient (MCD) diet for 6 weeks. A: Liver sections stained with hematoxylin and eosin for assessment of steatosis and inflammation. Nonalcoholic fatty liver disease (NAFLD) activity scores were calculated based on histologic evaluation of steatosis and inflammation. B: Hepatic mRNA expression levels of adipokines [tumor necrosis factor (TNF)- $\alpha$ and adiponectin] determined by real-time quantitative RT-PCR shown as fold change compared with those in the MCS diet-fed WT mice. C: Hepatic mRNA levels of proliferator-activated receptor gamma (PPAR $\gamma$ ), LFABP, and LPL determined by real-time quantitative RT-PCR and shown as fold change compared with those in the MCS diet-fed WT mice. Data are expressed as means \pm SEM per group. $n=6$ mice in the MCS group; $n=8$ mice in the MCD group. ${ }^{\star} P<0.05$ (two-tailed $t$-test). Original magnification: $\times 100$ (A, top row); $\times 200$ (A, bottom row). 


\section{A}

A Cont-ODN IRS 661

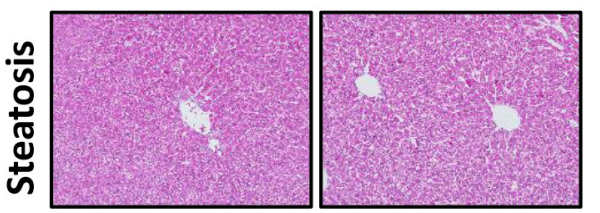

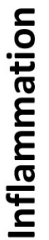

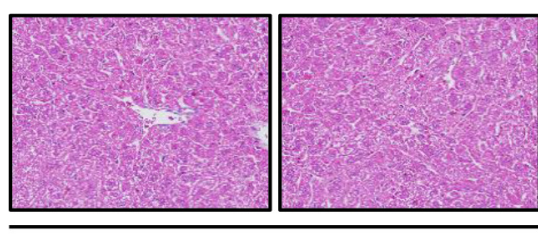

MCS

\section{Cont-ODN IRS 661}
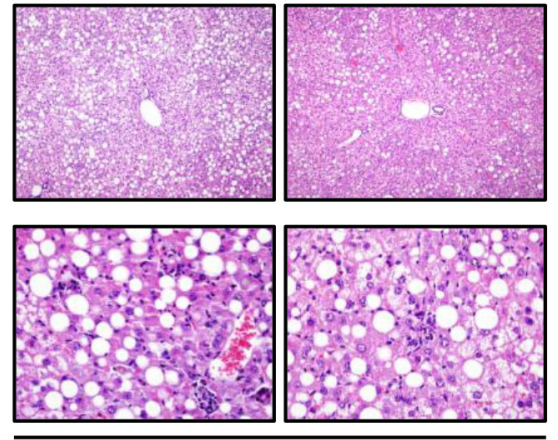

MCD

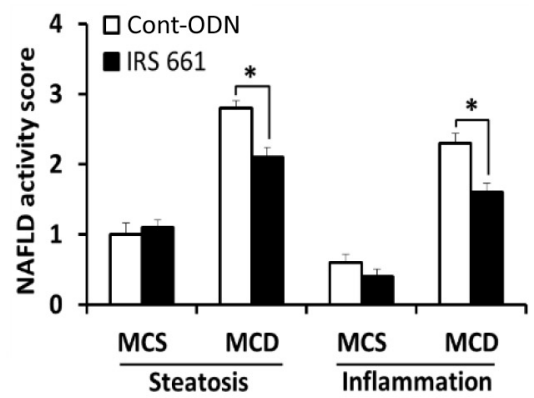

B
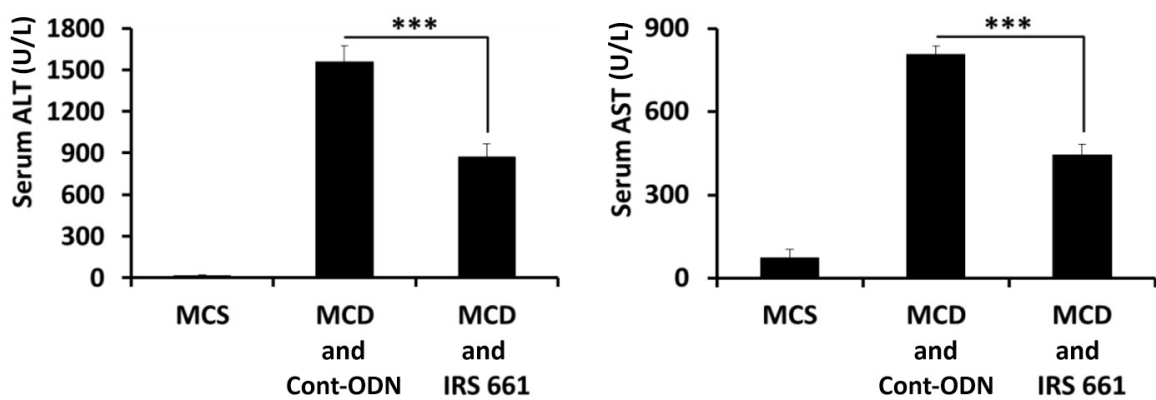

C
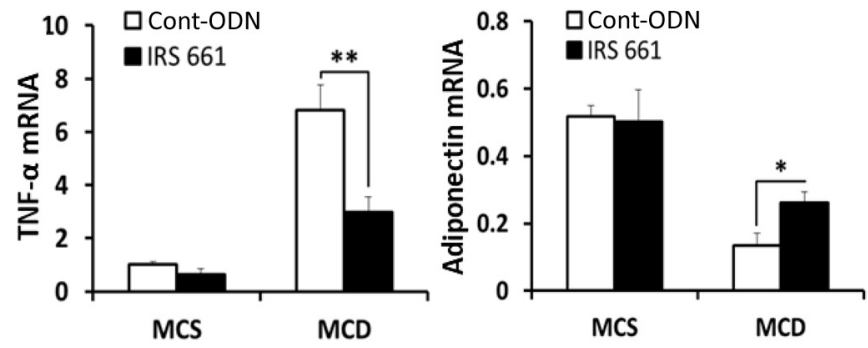

D
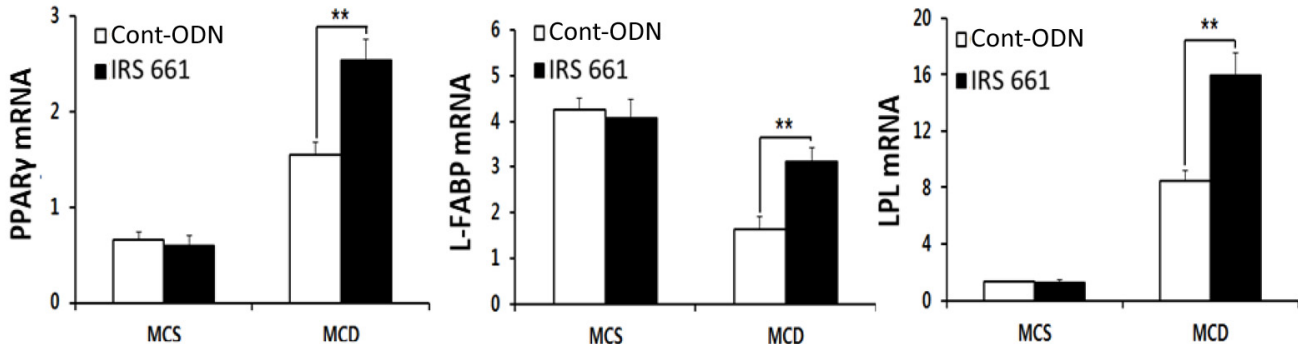

Figure 7 Toll-like receptor 7 (TLR7) antagonism with immunoregulatory sequence (IRS) 661 reduces severity of nonalcoholic steatohepatitis. IRS $661-$ and control (Cont)- oligodeoxyribonucleotide (ODN)-treated mice were fed a methionine-choline-sufficient (MCS) or methionine-choline-deficient (MCD) diet for 6 weeks. A: Liver sections stained with hematoxylin and eosin for assessment of steatosis and inflammation. Nonalcoholic fatty liver disease (NAFLD) activity scores were calculated. B: Serum levels of alanine aminotransferase (ALT) and aspartate aminotransferase (AST). C: Hepatic mRNA levels of adipokines [adiponectin and tumor necrosis factor (TNF)- $\alpha$ ] measured by real-time quantitative RT-PCR shown as fold change compared with those in the Cont-0DN and MCS-treated mice. D: Hepatic mRNA levels of proliferator-activated receptor gamma (PPAR $\gamma$ ), LFABP, and LPL determined by real-time quantitative RT-PCR shown as fold change compared with those in the Cont-ODN- and MCS-treated mice. Data are expressed as means \pm SEM per group. $n=6$ mice in the IRS 661 and Cont-ODN groups; $n=8$ mice in the MCS and MCD groups. ${ }^{*} P<0.05,{ }^{*} * P<0.01$, and ${ }^{* * *} P<0.001$ (two-tailed $t$-test). Original magnification: $\times 100$ (A, top row); $\times 400$ (A, bottom row).

IRS 661-treated mice than that in control ODN-treated mice. Reduced liver injury in IRS 661-treated mice was confirmed by significantly lower levels of serum ALT and AST (Figure 7B). In analysis for hepatic adipokine levels,
IRS 661 -treated mice had a significant decrease of TNF- $\alpha$, whereas adiponectin was conversely significantly increased in IRS 661-treated mice fed with an MCD diet (Figure 7C). Reduced lipid accumulation in IRS 661-treated mice was 


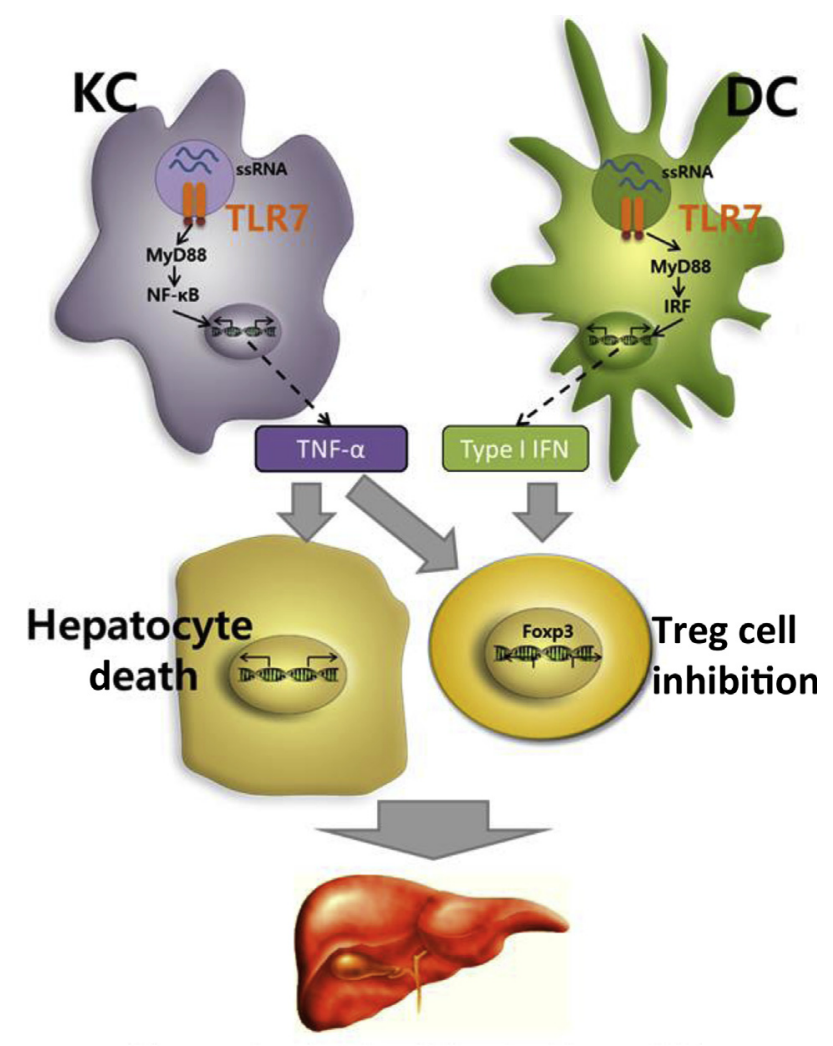

\section{NASH}

Figure 8 Schematic presentation showing toll-like receptor 7 (TLR7)dependent nonalcoholic steatohepatitis (NASH) progression by inhibiting T regulatory (Treg) cells. TLR7 signaling activates Kupffer cells (KCS) and dendritic cells (DCs) to produce tumor necrosis factor (TNF)- $\alpha$ and type I interferon (IFN), which in turn will induce hepatocyte damages and inhibit Treg cell activity. Thus, manipulating the TLR7-Treg axis might be useful as a novel therapeutic strategy to treat NASH. IRF, interferon regulatory factor; ssRNA, single-stranded RNA.

confirmed by higher expression levels of PPAR $\gamma$ and its target genes (Figure 7D). Taken together, these results support the notion that TLR7 signaling plays a key role in the pathogenesis of NASH.

\section{Discussion}

TLR7 signaling induces the production of type I IFNs and TNF- $\alpha$ through IRF7 and NF- $\kappa$ B activation, respectively. ${ }^{34,35}$ Recently, it has been reported that TLR7 can regulate lipid accumulation in hepatocytes by inducing autophagy. ${ }^{18}$ Although simple steatosis has been proposed as the first hit of NASH development, steatohepatitis is a clinically important stage. However, the mechanistic role of TLR7 signaling in steatohepatitis has not been fully elucidated yet. The present study found that TLR7-deficient mice had ameliorated NASH compared with WT mice after an MCD diet. Furthermore, our data indicate that TNF- $\alpha$-induced hepatocyte death and type I IFN- or TNF- $\alpha$-dependent Treg cell apoptosis were pivotal in the progression of NASH based on experiments using IFNAR1-deficient, TLR7-deficient, or
DEREG mice. Consequently, we concluded that TLR7 signaling may promote NASH through regulation of Treg cell activities and hepatocyte death.

Several lines of evidence support that TLR7-dependent inhibition of Treg cells enhances NASH. First, Treg cell-mediated detrimental role of TLR7 and its downstream cytokines, TNF- $\alpha$ and type I IFN, have been well documented using various models. ${ }^{38-41}$ Second, hepatic expression of Foxp3, a key transcription factor for immunosuppressive activity of Treg cells,${ }^{37}$ is significantly higher in TLR7-deficient mice and Foxp3 ${ }^{+}$DEREG mice have more severe NASH than WT mice. Third, similar to TLR7 deficiency, inactivation of type I IFN signaling protected NASH and blocked Treg cell inhibition. Fourth, DCs are responsible cell type for the production of type I IFN, whereas KCs are mainly responsible for the production of TNF- $\alpha$ on TLR7 activation. Finally, TLR7 activation by R848 inhibits Treg cells through the production of TNF- $\alpha$ and type I IFN. Taken together, our results suggest that TLR7 activation-mediated TNF- $\alpha$ and type I IFN production are responsible for NASH development by regulating Treg cells and hepatocyte death (Figure 8).

Two possible mechanisms can activate innate immune system in NASH. First, translocated bacteria and their products can activate the innate immune network as exogenous ligands in NASH. ${ }^{5,42-44}$ In chronic liver diseases, including NASH, intestinal permeability is increased because of bacterial overgrowth or altered compositions of bacterial microflora. ${ }^{6}$ Systemic inflammation related to NASH also injures epithelial tight junctions, ${ }^{3}$ resulting in deregulation of intestinal barrier functions. Indeed, plasma levels of LPS are elevated in patients with NASH. ${ }^{7}$ Previous reports have found that TLR4, a receptor for LPS, can promote steatohepatitis and fibrosis. ${ }^{9,43}$ Increased bacterial nucleic acid (DNA and RNA) are also increased in the liver tissue of patients with $\mathrm{NASH},{ }^{45}$ suggesting that translocated bacterial RNA could act as exogenous ligand in NASH. Second, accumulating evidence indicates that endogenous ligands released from damaged or stressed tissues designated as damaged tissue-associated molecular patterns can also signal through TLRs. ${ }^{46}$ Engagement of TLRs by endogenous ligands could be a major trigger of inflammation. Recent studies have suggested that RNA released from damaged tissue or contained within endocytosed cells might serve as a ligand for TLR $3{ }^{47}$ Although it has been suggested that TLR3 can recognize hostderived single-stranded RNA, TLR7 is a more relevant receptor for single-stranded RNA generated by apoptotic cells than TLR3. ${ }^{12,13}$ Therefore, TLR7 was studied as a receptor for nucleic acid because it might play an important role in this disease.

To clarify downstream immunity of TLR7 signaling, IFNAR1-deficient mice were used and a TNF- $\alpha$ inhibition experiment performed. Similar to TLR7-deficient mice, IFNAR1-deficient mice had reduced steatohepatitis compared with WT mice, suggesting that the TLR7-type I 
IFN axis had a detrimental role in NASH. In response to MCD diet-induced NASH, increased Foxp $3^{+}$Treg cells were evident in livers of TLR7-deficient and IFNAR1deficient mice compared with those in livers of WT mice. Conversely, IFN- $\alpha_{4}$ expression was comparable between WT and DEREG mice (data not shown), suggesting that IFN- $\alpha_{4}$ is an upstream regulator for Treg cell activities. Furthermore, TNF- $\alpha$ directly induced hepatocyte damage along with oxidative stress, whereas pentoxifylline treatment significantly recovered Foxp3 expression in response to R848. Therefore, it was speculated that TLR7-induced progression of NASH might be partially mediated by TNF- $\alpha$ and type I IFN. This notion is consistent with a previous report $^{18}$ and the data indicating significantly increased hepatic Foxp $3^{+}$Treg cells in TLR7-deficient mice compared with those in WT mice. Moreover, treatment with the TLR7 antagonist IRS 661 ameliorated NASH development. Taken together, these findings suggest that increased Treg cells are responsible for ameliorating NASH in TLR7 or IFNAR1-deficient mice.

Although clodronate liposomes target mainly KCs, effects of $\mathrm{KC}$ depletion on liver diseases have been controversial according to the literature. ${ }^{48,49}$ In the present study, Foxp3 expression was examined after injection of clodronate liposome. Clodronate injection did not change the expression of Foxp3 compared with the R848-treated control group (data not shown). However, pentoxifylline (an inhibitor of TNF- $\alpha$ production) treatment significantly increased the Foxp3 expression (Figure 5D). A previous report indicated that the pretreatment of clodronate markedly decreased the proportion of the $\mathrm{CD} 68^{+} / \mathrm{F} 4 / 80^{+} \mathrm{KCs}$ (high phagocytic and reactive oxygen species-producing capacity), clodronate induces proportional increase of the $\mathrm{CD} 11 \mathrm{~b}^{+} / \mathrm{F} 4 / 80^{+}$(high TNF-producing capacity), ${ }^{50} \mathrm{sug}$ gesting that clodronate predominantly incorporated into $\mathrm{CD} 8^{+} \mathrm{KCs}$ may selectively deplete those cells. Because clodronate has off-target effects, such as depletion of monocytes $^{51}$ and often altered global immune system, functional compensation could occur, thereby masking or distorting the phenotypes of these mice. ${ }^{50}$ Therefore, pentoxifylline is a more appropriate approach than clodronate to validate the TNF- $\alpha$-induced Treg cell suppression effect.

Accumulating evidence suggests that TNF- $\alpha$ or type I IFN induces apoptosis of Treg cells. ${ }^{40,52,53}$ To elucidate the mechanism of TLR7-mediated Treg cell suppression, type I IFN and TNF- $\alpha$ were depleted by DT injection in CD11c-DT receptor mice and pentoxifylline treatment, respectively, because DCs are the major cell type for production of type I IFN ${ }^{36}$ and pentoxifylline inhibits TNF- $\alpha$ production. In the present study, in vivo activation of TLR7 by R848 injection increased apoptosis of Treg cells in the liver. Of interest, blockade of type I IFN or TNF- $\alpha$ significantly inhibited apoptosis of these cells. These results suggest that both TNF- $\alpha$ and type I IFN are cytokines responsible for regulating Treg cells by the induction of apoptosis.
In summary, TLR7 signaling activates TNF- $\alpha$ and type I IFN signaling, thus triggering the hepatocyte death and Treg cell suppression. This pathway plays a pivotal role in endogenous progression of NASH. Furthermore, we clarified that hepatic Foxp $3^{+}$Treg cells were key regulators of NASH pathogenesis. These findings indicate, for the first time, that stimulation of TLR7 promotes hepatocyte damage followed by steatohepatitis by inhibiting protective Treg cells. Understanding TLR7-Treg cell mechanisms will offer valuable insights to the prevention and treatment of NASH.

\section{Acknowledgments}

TLR7-deficient mice were provided by Dr. Shizou Akira (Osaka University, Suita, Japan). DEREG mice were provided by Dr. Tim Sparwasser (Technische Universität München, Munich, Germany).

\section{Supplemental Data}

Supplemental material for this article can be found at https://doi.org/10.1016/j.ajpath.2018.07.011.

\section{References}

1. Roberts EA: Nonalcoholic steatohepatitis in children. Curr Gastroenterol Rep 2003, 5:253-259

2. Powell EE, Cooksley WG, Hanson R, Searle J, Halliday JW, Powell LW: The natural history of nonalcoholic steatohepatitis: a follow-up study of forty-two patients for up to 21 years. Hepatology 1990, 11:74-80

3. Miele L, Valenza V, La Torre G, Montalto M, Cammarota G, Ricci R, Masciana R, Forgione A, Gabrieli ML, Perotti G, Vecchio FM, Rapaccini G, Gasbarrini G, Day CP, Grieco A: Increased intestinal permeability and tight junction alterations in nonalcoholic fatty liver disease. Hepatology 2009, 49:1877-1887

4. Son G, Kremer M, Hines IN: Contribution of gut bacteria to liver pathobiology. Gastroenterol Res Pract 2010, 2010. 453563

5. Brun P, Castagliuolo I, Di Leo V, Buda A, Pinzani M, Palu G, Martines D: Increased intestinal permeability in obese mice: new evidence in the pathogenesis of nonalcoholic steatohepatitis. Am J Physiol Gastrointest Liver Physiol 2007, 292:G518-G525

6. Wu WC, Zhao W, Li S: Small intestinal bacteria overgrowth decreases small intestinal motility in the NASH rats. World J Gastroenterol 2008, 14:313-317

7. Farhadi A, Gundlapalli S, Shaikh M, Frantzides C, Harrell L, Kwasny MM, Keshavarzian A: Susceptibility to gut leakiness: a possible mechanism for endotoxaemia in non-alcoholic steatohepatitis. Liver Int 2008, 28:1026-1033

8. Csak T, Velayudham A, Hritz I, Petrasek J, Levin I, Lippai D, Catalano D, Mandrekar P, Dolganiuc A, Kurt-Jones E, Szabo G: Deficiency in myeloid differentiation factor-2 and toll-like receptor 4 expression attenuates nonalcoholic steatohepatitis and fibrosis in mice. Am J Physiol Gastrointest Liver Physiol 2011, 300: G433-G441

9. Rivera CA, Adegboyega P, van Rooijen N, Tagalicud A, Allman M, Wallace M: Toll-like receptor-4 signaling and Kupffer cells play pivotal roles in the pathogenesis of non-alcoholic steatohepatitis. J Hepatol 2007, 47:571-579 
10. Eberle F, Sirin M, Binder M, Dalpke AH: Bacterial RNA is recognized by different sets of immunoreceptors. Eur J Immunol 2009, 39: 2537-2547

11. Mancuso G, Gambuzza M, Midiri A, Biondo C, Papasergi S, Akira S, Teti G, Beninati C: Bacterial recognition by TLR7 in the lysosomes of conventional dendritic cells. Nat Immunol 2009, 10:587-594

12. Guiducci C, Tripodo C, Gong M, Sangaletti S, Colombo MP, Coffman RL, Barrat FJ: Autoimmune skin inflammation is dependent on plasmacytoid dendritic cell activation by nucleic acids via TLR7 and TLR9. J Exp Med 2010, 207:2931-2942

13. Barrat FJ, Meeker T, Gregorio J, Chan JH, Uematsu S, Akira S, Chang B, Duramad O, Coffman RL: Nucleic acids of mammalian origin can act as endogenous ligands for Toll-like receptors and may promote systemic lupus erythematosus. J Exp Med 2005, 202: $1131-1139$

14. Miura K, Kodama Y, Inokuchi S, Schnabl B, Aoyama T, Ohnishi H, Olefsky JM, Brenner DA, Seki E: Toll-like receptor 9 promotes steatohepatitis by induction of interleukin-1beta in mice. Gastroenterology 2010, 139:323-334.e7

15. Seki E, De Minicis S, Osterreicher CH, Kluwe J, Osawa Y, Brenner DA, Schwabe RF: TLR4 enhances TGF-beta signaling and hepatic fibrosis. Nat Med 2007, 13:1324-1332

16. Watanabe A, Hashmi A, Gomes DA, Town T, Badou A, Flavell RA, Mehal WZ: Apoptotic hepatocyte DNA inhibits hepatic stellate cell chemotaxis via toll-like receptor 9. Hepatology 2007, 46: $1509-1518$

17. Gabele E, Muhlbauer M, Dorn C, Weiss TS, Froh M, Schnabl B, Wiest R, Scholmerich J, Obermeier F, Hellerbrand C: Role of TLR9 in hepatic stellate cells and experimental liver fibrosis. Biochem Biophys Res Commun 2008, 376:271-276

18. Kim S, Park S, Kim B, Kwon J: Toll-like receptor 7 affects the pathogenesis of non-alcoholic fatty liver disease. Sci Rep 2016, 6: 27849

19. McCuskey RS, Ito Y, Robertson GR, McCuskey MK, Perry M, Farrell GC: Hepatic microvascular dysfunction during evolution of dietary steatohepatitis in mice. Hepatology 2004, 40:386-393

20. Rinella ME, Green RM: The methionine-choline deficient dietary model of steatohepatitis does not exhibit insulin resistance. J Hepatol 2004, 40:47-51

21. Diehl AM: Lessons from animal models of NASH. Hepatol Res 2005, 33:138-144

22. Lahl K, Loddenkemper C, Drouin C, Freyer J, Arnason J, Eberl G, Hamann A, Wagner H, Huehn J, Sparwasser T: Selective depletion of Foxp3+ regulatory T cells induces a scurfy-like disease. J Exp Med 2007, 204:57-63

23. Committee for the Update of the Guide for the Care and Use of Laboratory AnimalsNational Research Council: Guide for the Care and Use of Laboratory Animals: Eighth Edition. Washington, DC, National Academies Press, 2011

24. Rangnekar AS, Lammert F, Igolnikov A, Green RM: Quantitative trait loci analysis of mice administered the methionine-choline deficient dietary model of experimental steatohepatitis. Liver Int 2006, 26:1000-1005

25. Kleiner DE, Brunt EM, Van Natta M, Behling C, Contos MJ, Cummings OW, Ferrell LD, Liu YC, Torbenson MS, Unalp-Arida A, Yeh M, McCullough AJ, Sanyal AJ: Design and validation of a histological scoring system for nonalcoholic fatty liver disease. Hepatology 2005, 41:1313-1321

26. Wu CW, Chu ES, Lam CN, Cheng AS, Lee CW, Wong VW, Sung JJ, Yu J: PPARgamma is essential for protection against nonalcoholic steatohepatitis. Gene Ther 2010, 17:790-798

27. Gupte AA, Liu JZ, Ren Y, Minze LJ, Wiles JR, Collins AR, Lyon CJ, Pratico D, Finegold MJ, Wong ST, Webb P, Baxter JD, Moore DD, Hsueh WA: Rosiglitazone attenuates age- and dietassociated nonalcoholic steatohepatitis in male low-density lipoprotein receptor knockout mice. Hepatology 2010, 52:2001-2011
28. George J, Liddle C: Nonalcoholic fatty liver disease: pathogenesis and potential for nuclear receptors as therapeutic targets. Mol Pharm 2008, 5:49-59

29. Liu L, Yu S, Khan RS, Ables GP, Bharadwaj KG, Hu Y, Huggins LA, Eriksson JW, Buckett LK, Turnbull AV, Ginsberg HN, Blaner WS, Huang LS, Goldberg IJ: DGAT1 deficiency decreases PPAR expression and does not lead to lipotoxicity in cardiac and skeletal muscle. J Lipid Res 2011, 52:732-744

30. Rinella ME, Elias MS, Smolak RR, Fu T, Borensztajn J, Green RM: Mechanisms of hepatic steatosis in mice fed a lipogenic methionine choline-deficient diet. J Lipid Res 2008, 49:1068-1076

31. Armstrong D, Browne R: The analysis of free radicals, lipid peroxides, antioxidant enzymes and compounds related to oxidative stress as applied to the clinical chemistry laboratory. Adv Exp Med Biol 1994, 366:43-58

32. Herrmann JL, Beham AW, Sarkiss M, Chiao PJ, Rands MT, Bruckheimer EM, Brisbay S, McDonnell TJ: Bcl-2 suppresses apoptosis resulting from disruption of the NF-kappa B survival pathway. Exp Cell Res 1997, 237:101-109

33. Han J, Huez G, Beutler B: Interactive effects of the tumor necrosis factor promoter and 3'-untranslated regions. J Immunol 1991, 146: $1843-1848$

34. Akira S, Takeda K: Toll-like receptor signalling. Nat Rev Immunol 2004, 4:499-511

35. Hemmi H, Kaisho T, Takeuchi O, Sato S, Sanjo H, Hoshino K, Horiuchi T, Tomizawa H, Takeda K, Akira S: Small anti-viral compounds activate immune cells via the TLR7 MyD88-dependent signaling pathway. Nat Immunol 2002, 3:196-200

36. Roh YS, Park S, Kim JW, Lim CW, Seki E, Kim B: Toll-like receptor 7-mediated type I interferon signaling prevents cholestasis- and hepatotoxin-induced liver fibrosis. Hepatology 2014, 60:237-249

37. Roh YS, Park S, Lim CW, Kim B: Depletion of Foxp3+ regulatory t cells promotes profibrogenic milieu of cholestasis-induced liver injury. Dig Dis Sci 2015, 60:2009-2018

38. Hackl D, Loschko J, Sparwasser T, Reindl W, Krug AB: Activation of dendritic cells via TLR7 reduces Foxp3 expression and suppressive function in induced Tregs. Eur J Immunol 2011, 41: $1334-1343$

39. Nie H, Zheng Y, Li R, Guo TB, He D, Fang L, Liu X, Xiao L, Chen X, Wan B, Chin YE, Zhang JZ: Phosphorylation of FOXP3 controls regulatory $\mathrm{T}$ cell function and is inhibited by TNF-alpha in rheumatoid arthritis. Nat Med 2013, 19:322-328

40. Srivastava S, Koch MA, Pepper M, Campbell DJ: Type I interferons directly inhibit regulatory $\mathrm{T}$ cells to allow optimal antiviral $\mathrm{T}$ cell responses during acute LCMV infection. J Exp Med 2014, 211: 961-974

41. Bhattacharya A, Hegazy AN, Deigendesch N, Kosack L, Cupovic J, Kandasamy RK, Hildebrandt A, Merkler D, Kuhl AA, Vilagos B, Schliehe C, Panse I, Khamina K, Baazim H, Arnold I, Flatz L, Xu HC, Lang PA, Aderem A, Takaoka A, Superti-Furga G, Colinge J, Ludewig B, Lohning M, Bergthaler A: Superoxide dismutase 1 protects hepatocytes from type i interferon-driven oxidative damage. Immunity 2015, 43:974-986

42. Kawai T, Akira S: The roles of TLRs, RLRs and NLRs in pathogen recognition. Int Immunol 2009, 21:317-337

43. Seki E, Brenner DA: Toll-like receptors and adaptor molecules in liver disease: update. Hepatology 2008, 48:322-335

44. Szabo G, Dolganiuc A, Mandrekar P: Pattern recognition receptors: a contemporary view on liver diseases. Hepatology 2006, 44:287-298

45. Alisi A, Ceccarelli S, Panera N, Nobili V: Causative role of gut microbiota in non-alcoholic fatty liver disease pathogenesis. Front Cell Infect Microbiol 2012, 2:132

46. Marshak-Rothstein A: Toll-like receptors in systemic autoimmune disease. Nat Rev Immunol 2006, 6:823-835

47. Kariko K, Ni H, Capodici J, Lamphier M, Weissman D: mRNA is an endogenous ligand for Toll-like receptor 3. J Biol Chem 2004, 279 : $12542-12550$ 
48. Raptis DA, Limani P, Jang JH, Ungethum U, Tschuor C, Graf R, Humar B, Clavien PA: GPR120 on Kupffer cells mediates hepatoprotective effects of omega3-fatty acids. J Hepatol 2014, 60: 625-632

49. Devey L, Ferenbach D, Mohr E, Sangster K, Bellamy CO, Hughes J, Wigmore SJ: Tissue-resident macrophages protect the liver from ischemia reperfusion injury via a heme oxygenase-1-dependent mechanism. Mol Ther 2009, 17:65-72

50. Kinoshita M, Uchida T, Sato A, Nakashima M, Nakashima H, Shono S, Habu Y, Miyazaki H, Hiroi S, Seki S: Characterization of two F4/80-positive Kupffer cell subsets by their function and phenotype in mice. J Hepatol 2010, 53:903-910
51. Tosello-Trampont AC, Landes SG, Nguyen V, Novobrantseva TI, Hahn YS: Kuppfer cells trigger nonalcoholic steatohepatitis development in diet-induced mouse model through tumor necrosis factor-alpha production. J Biol Chem 2012, 287: 40161-40172

52. Toubi E, Kessel A, Mahmudov Z, Hallas K, Rozenbaum M, Rosner I: Increased spontaneous apoptosis of CD4+CD25+ T cells in patients with active rheumatoid arthritis is reduced by infliximab. Ann N Y Acad Sci 2005, 1051:506-514

53. Nguyen DX, Ehrenstein MR: Anti-TNF drives regulatory $\mathrm{T}$ cell expansion by paradoxically promoting membrane TNF-TNF-RII binding in rheumatoid arthritis. J Exp Med 2016, 213:1241-1253 